\title{
Effects of epibiosis on consumer-prey interactions
}

\author{
M. Wahl ${ }^{1}$, M. E. Hay ${ }^{2}$ \& P. Enderlein ${ }^{1}$ \\ ${ }^{1}$ Zool. Instit., Univ.Kiel, D-24098 Kiel, Germany (e-mail: mwahl@zoologie.uni-kiel.de) \\ ${ }^{2}$ Univ. of North Carolina at Chapel Hill, Instit. Mar. Sci., Morehead City, NC 28557, U.S.A.
}

Key words: indirect effects, interaction modification, epibiosis, predation, herbivores, carnivores

\begin{abstract}
In many benthic communities predators play a crucial role in the population dynamics of their prey. Surface characteristics of the prey are important for recognition and handling by the predator. Because the establishment of an epibiotic assemblage on the surface of a basibiont species creates a new interface between the epibiotized organism and its environment, we hypothesised that epibiosis should have an impact on consumer-prey interactions. In separate investigations, we assessed how epibionts on macroalgae affected the susceptibility of the latter to herbivory by the urchin Arbacia punctulata and how epibionts on the blue mussel Mytilus edulis affected its susceptibility to predation by the shore crab Carcinus maenas.

Some epibionts strongly affected consumer feeding behavior. When epibionts were more attractive than their host, consumer pressure increased. When epibionts were less attractive than their host or when they were repellent, consumer pressure decreased. In systems that are controlled from the top-down, epibiosis can strongly influence community dynamics. For the Carcinus/Mytilus system that we studied, the insitu distribution of epibionts on mussels reflected the epibiosis-determined preferences of the predator. Both direct and indirect effects are involved in determining these epibiont-prey-consumer interactions.
\end{abstract}

\section{Introduction}

In succession theory, highest diversity occurs at an intermediate stage in a community's progression from low-diversity pioneer stage to a low-diversity climax stage. This theoretical development of a community is governed by recruitment, subsequent interference competition for resources, and exclusion of some species by consumers or stressful physical conditions (Connell \& Slatyer, 1977; Sousa, 1979). If left undisturbed, the elimination of inferior competitors or poor colonists leads to a low-diversity community dominated by a few species. In nature, however, this hypothetical climax is rarely reached. Physical (oxygen-deficiency, ice, storms...) and biological disturbances (predation, parasitism...) eliminate individuals or species and throw the community, or patches within the community, back to an earlier point in succession (e.g. Menge \& Sutherland, 1987; Lampert \& Sommer, 1993). Amplitude, frequency and regularity of disturbance determine its impact on the community (e.g. Sommer, 1995). In many marine communities, consumers (both herbivores and carnivores) constitute a major source of disturbance.

Consumer-prey interactions are necessarily mediated by the potential prey's body surface. Whether consumers forage using optical, olfactory or gustatory and tactile cues, the signals they perceive are a property of, or transmitted by, the prey's surface: shape, colour, scent, texture, consistency and so on. Also, many anticonsumer defenses are characteristics of the prey's surface: mimicry, camouflage, spines, mucus, toxins. The prey's body surface may thus be expected to play a primary role in its interactions with consumers.

Epibiosis, the colonisation of a living surface by sessile animals or plants, can substantially change the basibiont's surface properties. In fact, following epibiotic colonisation the basibiont/water interface is replaced by a basibiont/epibiont(s)/water interface. Successful consumption of a prey item occurs via 
four serial phases: (1) encounter $\rightarrow$ (2) recognition $\rightarrow$ (3) capture/handling $\rightarrow$ (4) consumption (after Lampert \& Sommer, 1993). Interference in any of these phases impairs consumption. The presence of epibionts on a prey's surface may interfere with phases 2 (recognition) or 3 (capture/handling), and probably not 4 (consumption), because most predators detect unpalatability during handling.

We hypothesised that consumer/prey interactions may be affected by epibiosis. The questions we asked were:

- Does epibiosis influence consumer pressure by modifying the preference behaviour of consumers?

- If so, do different epibiont species shift consumer/prey interactions in different directions (increase vs decrease of predation pressure)?

In this investigation, we studied the effects of epibiosis on both herbivory (sea urchin Arbacia punctulata grazing on macroalgae) and carnivory (the shore crab Carcinus maenas preying on the mussel Mytilus edulis).

\section{Material and methods}

\section{Herbivore-prey interactions}

Details on methodology and an expanded presentation or data are available in Wahl \& Hay (1995), but a short overview is provided below. Most prey algae were collected between 0.5 and $2 \mathrm{~m}$ below MLW from jetties and pilings around Morehead City and Beaufort ( $\left.32^{\circ} 42^{\prime} \mathrm{N}, 76^{\circ} 41^{\prime} \mathrm{W}\right)$, North Carolina, USA. Only the brown alga Zonaria was taken $41 \mathrm{~km}$ offshore from Wilmington, North Carolina, at a depth of $28 \mathrm{~m}$. Host seaweeds used in this study were the green alga Codium fragile, the brown algae Sargassum filipendula and Zonaria tournefortii and the red algae Gigartina acicularis, Gracilaria tikvahiae and Agardhiella subulata. Epibiont species found on one or more of these host species in sufficient abundance to be used in this investigation were the brown alga Ectocarpus sp. (on Sargassum, Codium, Gracilaria, and Agardhiella), the red algae Polysiphonia sp. (on Sargassum, Codium, Gigartina, Gracilaria, and Agardhiella) and Audouinella sp. (on Sargassum, and Codium), the bryozoans Bugula neritina (on Sargassum) and Membranipora membranacea (on Zonaria), and eggs of the gastropod Anachis floridana (on Sargassum). After their first introduction, all organisms will be referred to by their generic names.
All feeding assays were run with the omnivorous sea urchin, Arbacia punctulata, which is the most abundant inshore sea urchin and one of the most ecologically important herbivores in this area. Urchins were collected at Radio Island jetty near Beaufort, $\mathrm{NC}$, and kept in shallow flow-through tanks. Between assays, urchins were fed on a variety of available algae, mostly Gracilaria, Enteromorpha sp., Ulva sp., Gigartina, and Codium.

To determine how epibionts and hosts affected each other's probability of being (a) found and (b) eaten by this generalist grazer, we employed two experimental approaches. First, we tried to determine the position of each host or epibiont on Arbacia's feeding preference hierarchy. Secondly, we determined whether a host's susceptibility to urchin grazing changed if it was epiphytized. Because movement to a prey (= 'choice') and consumption of that prey were significantly correlated (Spearman $r=0.615, p=0.009$; see Wahl \& Hay [1995]), only choice data will be presented here.

All experiments were run in four $2.3 \mathrm{~m} \times 0.65 \mathrm{~m}$ $\times 0.15 \mathrm{~m}$ flow-through tanks. In each tank 10 urchins were fenced individually in plastic mesh cylinders $(\mathrm{d}=30 \mathrm{~cm}, \mathrm{~h}=20 \mathrm{~cm}, 1 \mathrm{~cm}$ mesh width). These 40 urchins were regarded as independent replicates. Urchins were always offered a two-way choice with the 2 prey items initially being positioned $20 \mathrm{~cm}$ from the urchin and separated from each other by 1 urchin diameter $(5-10 \mathrm{~cm})$. 'Choice' was determined by checking each replicate at about 30 minute intervals for the first 8-12 $\mathrm{h}$ of the experiment and recording which food was first contacted by the urchin's oral field.

To predict how a host's susceptibility to urchin grazing would change as a function of being fouled, the theoretical change in rank $(\Delta R)$ of a fouled host was computed as $\Delta R=R_{h}-\left(R_{e}+R_{h}\right) / 2$ where $R_{h}=$ the rank of the clean host and $R_{e}=$ the rank of the epiphyte on the urchin's preference hierarchy (see Wahl \& Hay, 1995).

\section{Carnivore-prey interactions}

All test organisms (the shore crab Carcinus maenas, as well as fouled and clean mussels Mytilus edulis) were collected by SCUBA from shallow near-shore habitats around Kiel (Western Baltic, $54^{\circ} 22^{\prime} \mathrm{N}, 10^{\circ} 09^{\prime}$ E). Between experiments, crabs were kept in a $2 \mathrm{~m}^{3}$ tank that was connected to a closed, recirculating system (volume: $5 \mathrm{~m}^{3}$, salinity: $17-18 \%$ o, temperature: $15{ }^{\circ} \mathrm{C}$.). They were fed with blue mussels collected from the same habitat. Mussels were kept in a sep- 
arate tank that was connected to the same seawater system as the crabs. Only mussels smaller than $5 \mathrm{~cm}$ shell length fall into the prey spectrum of the crabs used in the predation preference experiments. Mussels used for these tests were fouled by barnacles (Balanus improvisus), hydroids (Laomedeaflexuosa), bryozoans (Electra pilosa), or filamentous algae. All but the dominant epibiont species of the epibiotic assemblage on a given mussel were scraped off in order to avoid mixture of cues.

To test for the possibility that fouled and unfouled mussel differ in some predation-related property unrelated to the presence of epibionts (e.g., physiology, value as a food, ...), the shells of fouled mussels were thoroughly cleaned (after having noted the composition of their epibiotic community) and predation on these cleaned mussels was compared with predation on similar sized mussels that had not initially supported epibionts.

Experiments started within $36 \mathrm{~h}$ after the mussels had been collected. The preference experiments were run in a $250 \mathrm{~cm} \times 70 \mathrm{~cm} \times 15 \mathrm{~cm}$ sized flow-through table that was subdivided by movable walls into 12 compartments (L: $30 \mathrm{~cm}, \mathrm{~W}: 30 \mathrm{~cm}, \mathrm{H}: 15 \mathrm{~cm}$ ). The bottom of each compartment was covered with sand because crabs behaved more naturally and were less frantic if they were allowed to burrow. All experiments were run as two-way preference tests, where (in each replicated compartment) one crab was randomly offered two prey items. The crabs chose either between a clean and a fouled mussel, or between a clean mussel and an originally fouled, but then cleaned mussel. We positioned the mussels in the middle of each compartment and separated them by at least the distance of one crab-width. Care was taken to match mussel size in each replicate.

Feeding preference (= actual consumption of the first of the two mussels offered) was recorded. Crabs that had not fed after $12 \mathrm{~h}$ were replaced. Crabs and mussels were removed from the compartments as soon as one of the prey items had been consumed. They were only used once per test series. In order to distinguish between the effects of visual and olfactory cues in determining prey choice by the crabs, a different experimental set-up was used. In these experiments, successful feeding was precluded by the experimental set-up (see below), instead 'choice' as first contact between crab and prey was registered. To avoid disturbance of crab behaviour by a continuous presence of the experimenter, this survey had to be automated: each of the 2 prey items per compartment was placed in the centre of a circle (diameter $10 \mathrm{~cm}$ ) of six photo sensors hidden in the sand. Signals of the sensors, activated by the shadow of a crab contacting a prey, together with activation time were registered by computer. To produce only visual signals, prey (clean or fouled mussel) were offered to crabs in closed glass vessels that allowed crabs to see but not smell or touch the prey. To produce only chemical signals, prey (clean or fouled mussel) were offered to crabs in black but finely perforated vessels that allowed crabs to smell but not see or touch the prey.

\section{Natural distribution of Mussel-Epibiont-Associations}

At one of our experimental sites (an abandoned harbour), both mussels and crabs were very abundant. While mussels grew on all hard substrata, some of these substrata were inaccessible to crabs. In a SCUBA survey we assessed crab abundance (as an indicator for predation pressure by crabs) and the distribution of differently fouled mussels (clean, with barnacles, hydrozoans...) on various man-made substrata (pilings, ladders, ropes, pipes). Subsequently, we tested whether the observed epibiotic patterns could be explained by our data showing how epibionts affected crab feeding preferences.

To evaluate treatment effects, we used contingency table analyses or Fisher's exact test (if appropriate due to small cell sizes) and, when appropriate, a paired U-test.

\section{Results}

\section{Herbivore-prey interaction}

The generalist sea urchin Arbacia punctulata exhibited strong preferences among the 12 prey species offered (Figure 1). Potential prey could therefore be ranked linearly on a preference gradient from least (rank 12) to most (rank 1) preferred food. In the majority of cases, urchin preference differed significantly $(p<0.05)$ among the various prey species. Only at the extremes of the gradient did preferences became less distinct (group of least preferred: Ectocarpus 1, Sargassum, group of most preferred: Anachis eggs, Agardhiella, Ectocarpus 2). During this study, Ectocarpus sp. apparently changed food quality drastically between spring (E.1) and summer (E.2), probably due to physiological stress (Wahl \& Hay, 1995; Cronin and Hay, 1996). 


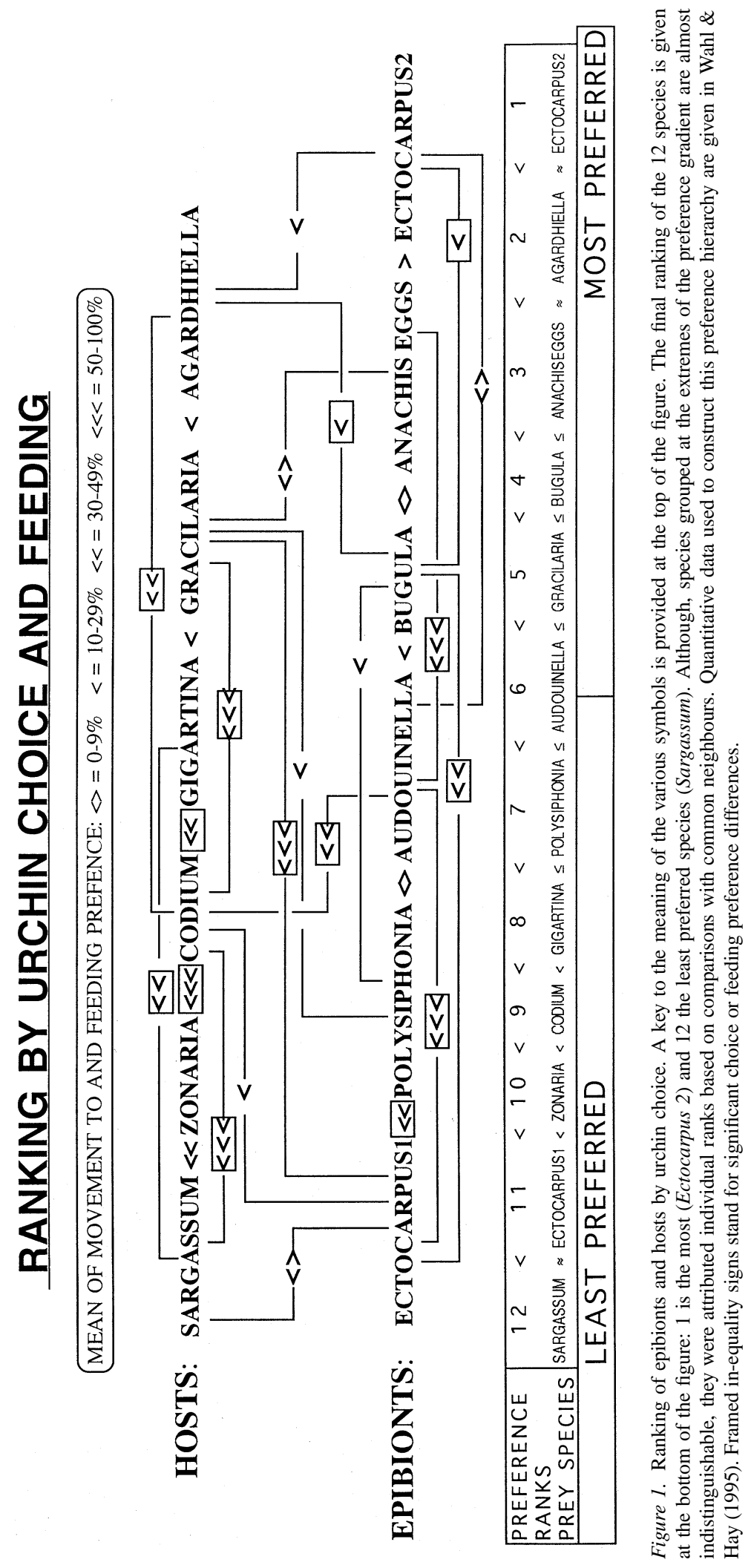


We predicted that the attractiveness or repulsiveness of a fouled alga would be determined by the relative food values of the epibionts and the basibiont based on the assumption that an epibiotic association combines characteristics of both epibionts and basibionts in approximately equal proportions. Surprisingly, this extreme simplification of calculating the preference rank of a fouled prey as the arithmetic mean of epibiont and basibiont preference ranks turned out to be a good predictor of how the urchins would react to the composite organism (Figure 2). Fouling by a more palatable epibiont enhanced consumption (shared doom), while colonization by less a preferred epibiont reduced consumption by the urchins (associational resistance). The greater the difference between epibiont and basibiont rank, the greater the epibiosis-induced change in how urchins treated the fouled host.

These effects of epibiosis can be strong enough to switch host algal position on the urchin's preference gradient, either increasing or decreasing an alga's susceptibility relative to other co-occurring seaweds (Figure 3). The ecological consequences for community dynamics are discussed later, but could be far-reaching.

\section{Carnivore-prey interactions}

Epibionts on mussels strongly modified predator-prey interactions (Figure 4). After cleaning, mussels originally bearing different epibionts (barnacles, hydrozoans) did not differ $(p>0.43)$ from unfouled mussels in their susceptibility to predation. Crabs consumed equal quantities of clean vs formerly hydrozoan-fouled mussels ( 15 vs $12, p=0.43$ ) and of clean vs formerly barnacle-fouled mussels ( 15 vs $18, p=0.47$ ). This shows that mussels without epibionts whether previously fouled or not did not differ in any property that produced a significant change in susceptibility to crab predation.

Fouling by filamentous algae did not affect the crab' predation on mussels ( 5 vs $5, p=1$ ), but fouling by barnacles or hydrozoans strongly influenced crab predation on the mussel host (Figure 4). Balanus improvisus was highly attractive and increased its host's susceptibility to crab predation by a factor of three. When given the choice between clean and barnacle-fouled mussels, Carcinus consumed 5 clean vs 15 epibiotized prey $(p=0.0021)$. In contrast, fouling by the hydroid Laomedea flexuosa had the opposite effect, and significantly lowered predation on host mussels $(p=0.0001)$. Crabs consumed 20 clean mussels, but only 4 mussels fouled by hydrozoans. This represents a 5 fold decrease in susceptibility. Only 5 mussels of the size class $3-$ $5 \mathrm{~cm}$ fouled by the bryozoan Electra pilosa could be found. This bryozoan-mussel association was taken 4 times as often as clean mussels, but, possibly due to the small number of replicates, this difference was not statistically significant $(p=0.11)$.

When offering the crabs mussels fouled by barnacles vs. hydrozoans, Carcinus exhibited an even more dramatic difference in predation preference than when one of the prey alternatives was a clean mussel. Nine crabs consumed the mussel bearing barnacles, while only one crab fed on the mussel carrying hydrozoans on its shell. This difference in predation was highly significant $(p<0.001)$.

Summarising, filamentous algae did not affect the host mussel's susceptibility to predation, barnacles increased susceptibility, and hydrozoans decreased susceptibility of the host mussel.

With unobstructed perception (all stimuli), 90\% of the crabs preferred barnacle-fouled over hydrozoanfouled mussels. For this most unequal pairing with regard to crab preference, we tried to determine whether the observed effects of epibionts on crab behaviour were caused by visual or olfactory properties of the epibiosis (Figure 5). When perceiving only visual cues (prey in glass vessels), the significant preference for barnacle-fouled mussels was lost. In fact, 8 out of 12 crabs first approached the (usually less preferred) hydrozoan-mussel association. When only olfactory stimuli were available to searching crabs (prey in perforated black vessels), 11 crabs first approached the hydrozoan-mussel association, whereas 13 crabs contacted the barnacle-mussel vessel in the first place. No preference was apparent $(p=0.58)$. If one considers not only the first but all contacts crabs made with the offered prey, then the search seems even more 'cueless'. 88 (barnacle-mussel) versus 99 (hydrozoan-mussel) and 211 (barnacle-mussel) versus 208 (hydrozoan-mussel) contacts made in the visual and olfactory search, respectively.

Summarising, neither optical nor olfactory properties of the epibionts per se are responsible for the observed effects of epibiosis on crab predation.

On the hard substrata investigated, Carcinus maenas was unevenly distributed, reflecting their epibenthic life-style. On substrata that did not reach the bottom (ropes, ladders, pipes) no crabs were found. These objects were classified as 'inaccessible' (to crabs). On pilings, accessible to crabs, Carcinus abundance exhibited a decreasing gradient from the bottom to the water surface (Figure 6). 


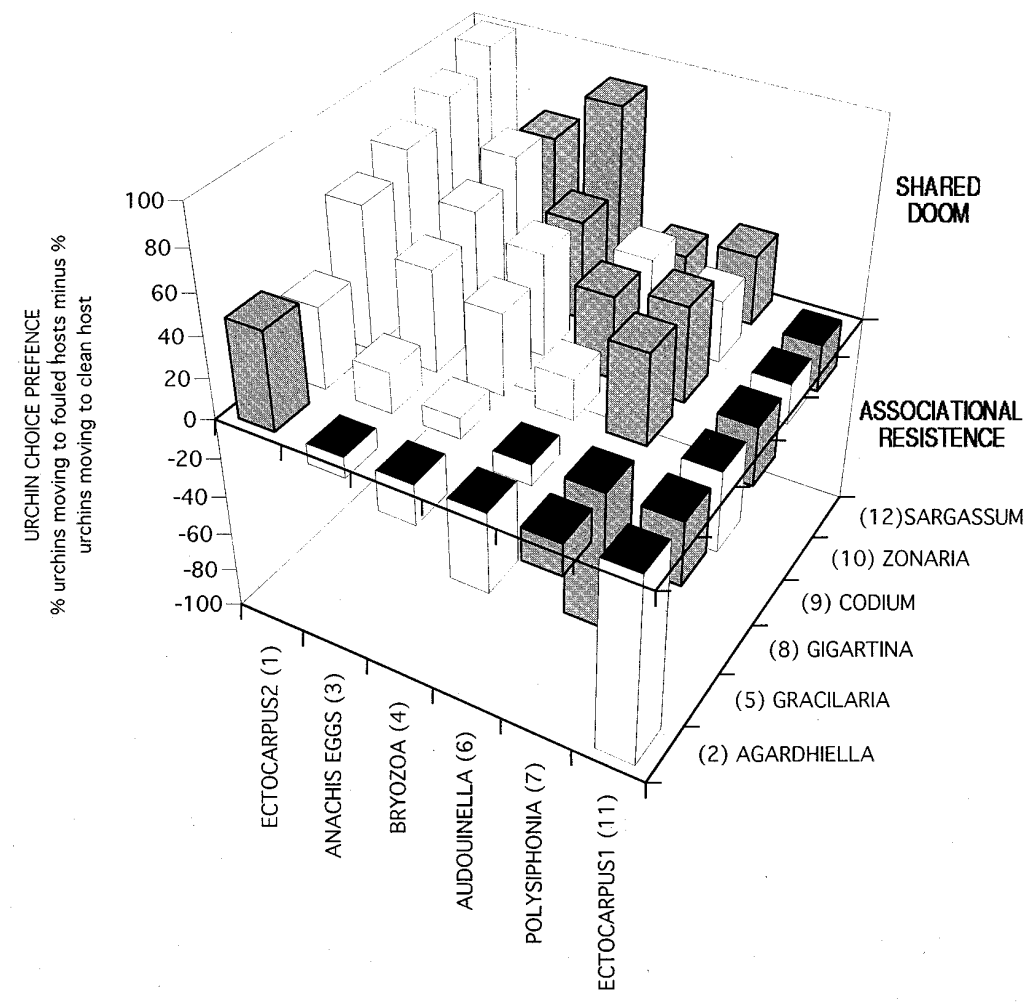

Figure 2. Predicted (white columns) and observed (shaded columns) changes in urchin choice of a prey species due to presence of epibionts. Positive values indicate shared doom effects; negative values indicate associational resistance effects. Columns with black bottoms represent negative changes. In this presentation shaded columns (= results) have replaced predicted (white) columns. Results match predictions well. For details of predictions see the text or Wahl \& Hay (1995).

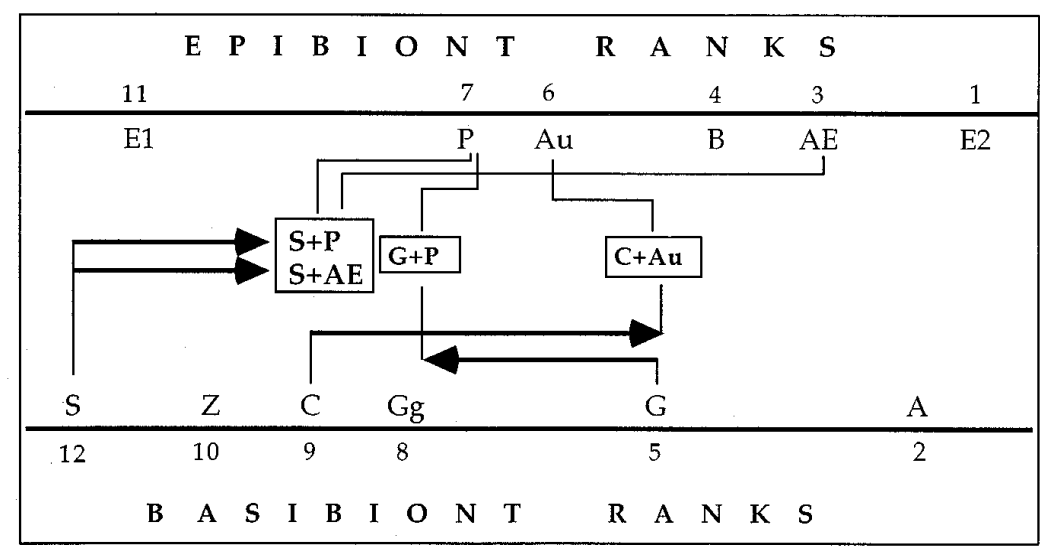

Figure 3. Rank shifts caused by epibiosis. Predator-prey interaction modification by epibionts may be strong enough to make prey species shift position on the urchin preference gradient. Thus, their susceptibility to grazing relative to neighboring prey species is altered. As an example, Codium when fouled by Audouinella surpasses the formarly preferred Gigartina in palatability and becomes equivalent to Gracilaria (formerly almost 6 ranks more attractive). 


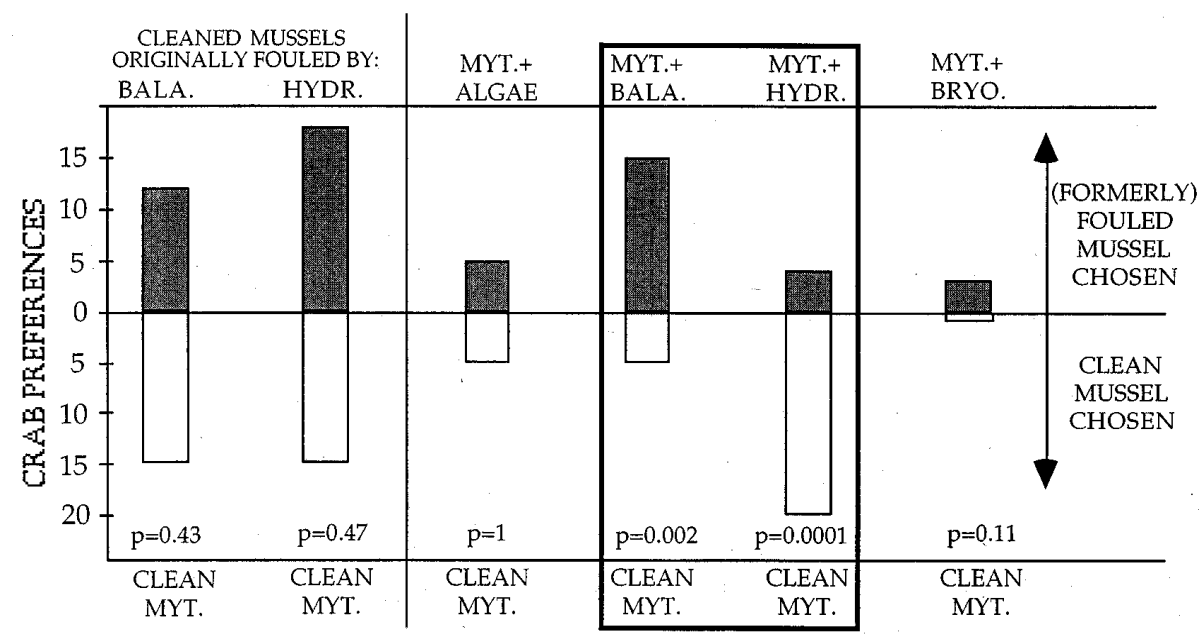

Figure 4. Crab feeding preferences when offered fouled, previously fouled, or clean mussels. $p$-values by Fisher's Exact test following a Contingency Table analysis. Abbreviations: Bala. $=$ barnacle B. improvisus, Hydr. $=$ hydroid L. flexuosa, Bryo. = bryozoan E. pilosa, Myt. = mussel M. edulis; y-axis: number of mussels consumed.

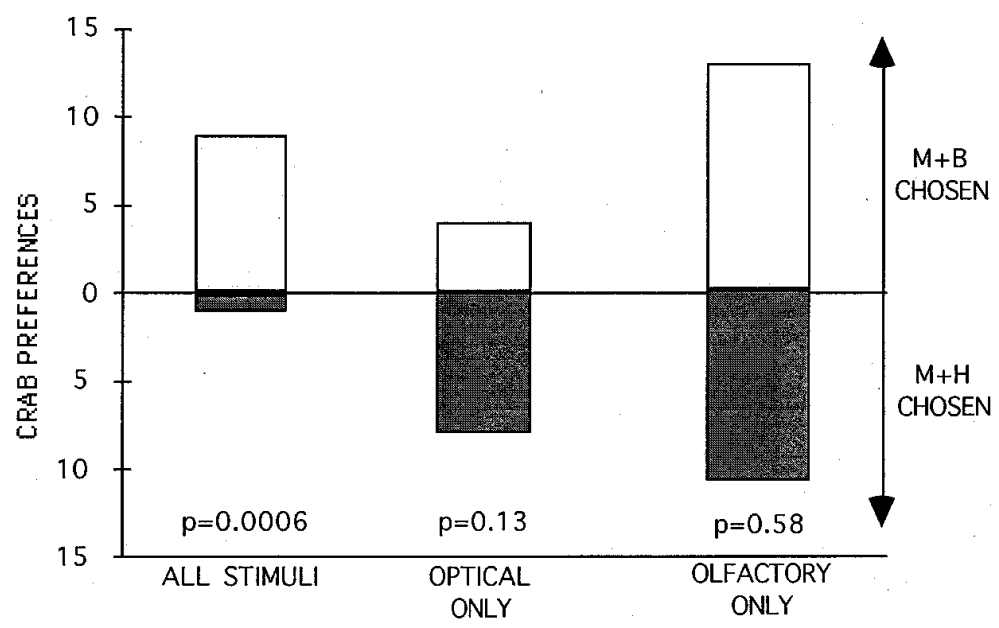

Figure 5. Preferences of crabs choosing between barnacle-fouled $(\mathrm{M}+\mathrm{B})$ and hydroid-fouled mussels $(\mathrm{M}+\mathrm{H})$ providing different stimuli. 'All stimuli' $=$ visual + olfactory + gustatory/tactile, 'Optical only' $=$ olfactory and gustatory/tactile stimuli suppressed, 'Olfactory only' $=$ visual and gustatory/tactile stimuli suppressed; $p$-values: Fisher's Exact following a Contingency Table analysis; y-axis: number of mussels consumed.

Mussels occurred at similar abundances on all substrata and at all investigated depths. In contrast, the distribution of epibiotic communities on mussels varied strongly (Figure 6). On substrata without crabs, 70$80 \%$ of the mussels were fouled by barnacles, less than $20 \%$ of the mussels, on average, were clean, and epibiotic hydrozoans did not occur. On substrata with crabs, clean mussels dominated (45-65\%), barnacles fouled $20-40 \%$ of the mussels, and abundance of hydrozoa fouled mussels increased with depth from $0 \%$ to 15 $20 \%$.
The most conspicuous result is that hydrozoanmussel associations occurred exclusively in the presence of Carcinus. The relative abundance of the former correlates directly with crab abundance (Spearman Rank Correlation, rho $=0.7, p=0.006$ ).

The relative abundance of the barnacle-mussel association correlates inversely with the abundances of hydrozoan-mussel epibioses (rho $=-0.71, p=0.013$ ) and with Carcinus density (rho $=-0.74, p=0.01$ ). 


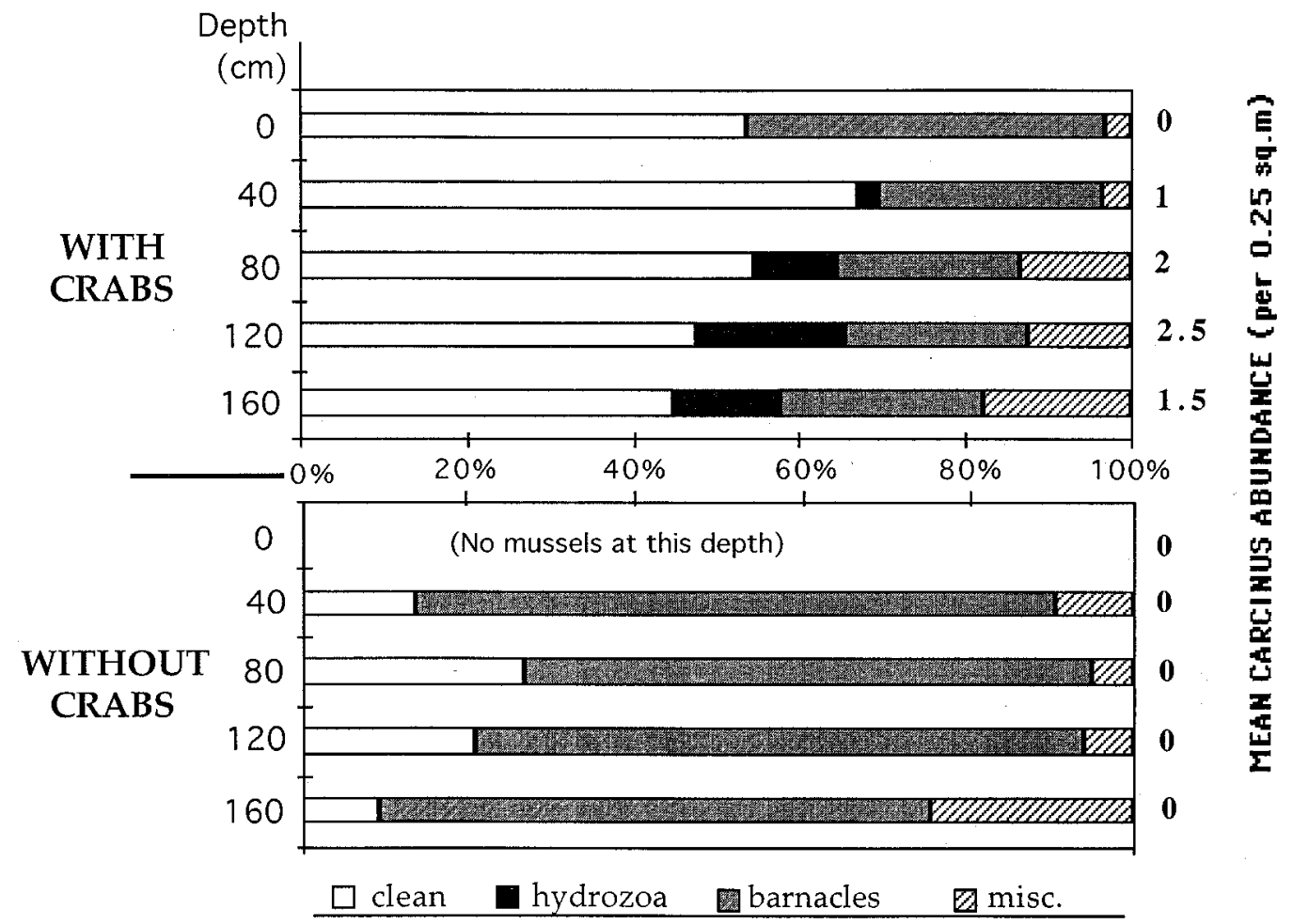

Figure 6. Proportional distribution (in \% of population) of mussels fouled by different epibiont species in habitats inaccessible (lower part) and more or less accessible (upper part) to crabs. 'misc.' = mussels fouled by algae, bryozoans or sponges. Crab abundances on the right side of the graph.

\section{Discussion}

Epibiosis can drastically alter basibiont susceptibility to both herbivores and carnivores. Epibionts ranking higher on a preference hierarchy than their host will increase predation (shared doom); those ranking lower in attractiveness will decrease predation (associational resistance) on their host. Finally, the distribution of mussel/epibiont associations at the one location inventoried seems to reflect the epibiont - dependent differential mortality of mussels when predators may have been strongly affecting the community.

We are aware of very few reports on the role of epibionts in affecting predator-prey interactions. Feifarek (1987) described how an epibiotic sponge impeded starfish predation on a spiny oyster, Barkai \& McQuaid (1988) found that whelks in shells overgrown by a bryozoan were resistant to lobster predation, and Gil-Turnes et al. (1989) reported that bacteria growing on the surface of shrimp embryos chemically defended the embryos from pathogenic fungi. Bach (1980) mentioned how normally immune corn may be moderately attacked by cucumber herbivores when grown intermixed with cucumber, Threlkeld et al. (1993) found that zooplankton may become more susceptible to predation when fouled, and epibiotic bryozoans have been shown to increase the attractiveness of kelp blades for grazing fishes (Bernstein \& Jung, 1979) and echinoids (Ryland, 1976). In contrast, Prescott (1990) could not discover any effect of scallop epibionts on predation by seagulls or whelks.

The two interaction webs investigated here differed not only in the type of basibiont prey (algae and animals, resp.) but also in the diet breadth of the consumer species. Arbacia punctulata is an extreme generalist and it consumed all host and epibiont species when the alternative was a neutral non-food (agar agar, Wahl \& Hay, 1995). Consequently, the urchins were not repelled by any epibiont. Rather the epibionts either enhanced or masked attractive signals of the basibiont. The facts that Arbacia is blind and that choice and consumption correlated so strongly imply that the urchins identify their preferred prey from a distance. The water-borne chemical signals responsi- 
ble are presumably exudates of the alga and, if fouled, its epibionts. Because increasing the biomass of a prey did not notably affect urchin preference (Wahl \& Hay, 1995), the species-specific chemical effects of the epibionts appeared to be responsible for the changes in foraging rather then these changes being caused by the fact that hosts with epibionts represent a larger resource than hosts alone.

The carnivorous generalist, Carcinus maenas, appeared to have more narrowly defined food choices than the urchin. Of the prey items offered, the crabs readily consumed Balanus and Mytilus, but did not eat the epibiotic alga or hydrozoan. Balanus (and probably the bryozoan Electra) enhanced predation on the mussels (shared doom), whereas the hydrozoan Laomedea reduced it (associational resistance). The red algal epibiont Ceramium did not affect predation rates.

For localisation and identification of a potential prey, Carcinus maenas may theoretically use cues on three informational levels: visual, olfactory, and gustatory/ tactile. Zimmer-Faust et al. (1995) have recently explored in detail the olfactory search behaviour of the blue crab Callinectes sapidus. They found that this crab species was capable of localising prey by binary comparison of chemical concentrations of cues inside and outside an odour plume originating from the prey. Our stimulus-experiments showed that in the case of Carcinus maenas neither visual nor olfactory information alone was sufficient to produce the clear preferential behaviour that the crab exhibited when all stimuli were offered. Either, only the simultaneous perception of visual and olfactory cues enables the crab to localise and identify preferred prey, or Carcinus also depends to a significant degree on gustatory/ tactile information for prey recognition. A prominent role in food search of the gustatory funnel-canal organs in the dactyl tips of Carcinus has been proposed by Schmidt \& Gnatzy (1987).

In predator-controlled (top-down) communities, such as the Baltic mussel population we studied, our lab results on crab preferences would lead us to expect that in situ predation pressure should (in part) depend on the kind of epibionts a mussel bears. Differential survival should produce observable patterns of mussel-epibiont distribution. Indeed, the SCUBA inventory of in situ mussel-epibiont associations showed that under natural conditions, epibiont species were not distributed randomly between habitats characterized by different densities of crabs. The different mussel-epibiont associations in crab-controlled as compared to crab-free habitats reflected clearly the unequal susceptibilities to predation of these different associations.

On mussels not accessible to Carcinus predation, the barnacle Balanus improvisus was clearly the dominant epibiont, clean mussels were relatively rare, and hydrozoan epibionts did not occur. In contrast, when crabs were present, the proportion of barnacle-fouled mussels was much reduced, clean mussels dominated the population, and hydrozoan-fouled mussels (which are resistant to crab predation) correlated positively with crab abundance.

Thus, epibiotic communities differed sharply as a function of crab absence or presence. We believe, this may be explained by the effects of the different epibiont species on Carcinus feeding. Carcinus feeds preferentially on barnacles and on barnacle-fouled mussels. In habitats accessible to crabs, this preference is reflected by a reduced proportion of mussels bearing barnacles, accompanied by an increased proportion of clean (or rather cleaned?) mussels. The 'attractant/decoy scenario' of Atsatt \& O'Dowd (1976) describes how species may benefit from the presence of more preferable species, the latter attracting a common predator away from the former. In an earlier paper (Wahl \& Hay 1995) it was suggested that epibiosis might be too close an association for many large predators to distinguish between attractive epibiont and less palatable basibiont. Such an association should rather lead to shared doom. While this observation was true for urchins, it may not apply to the same extent to the more delicately discriminating crabs. In fact, during the experiments presented here, Carcinus several times only consumed highly attractive epibionts (e.g. barnacles) without feeding on the basibiotic mussel. It is conceivable, that a rich barnacle aufwuchs on mussels could sometimes satisfy the nutritional needs of $\mathrm{Carci}$ nus thus sparing the basibiotic mussels from predation. Such a situation would correspond to the 'attractant/decoy scenario'. Possibly, a portion of the clean mussel contingent had actually been cleaned of their barnacles by selectively feeding crabs.

The associational resistance effect of hydrozoan epibionts may be responsible for the observation, that mussel-hydrozoan associations increased in dominance with increasing predation pressure. The absence of epibiotic hydrozoa from mussels inaccessible to crabs could suggest that barnacles, released from crab predation, out-compete hydrozoans. An alternative explanation could be that in the absence of crabs hydrozoan-predators (e.g. nudibranchs) proliferate. Indeed, without predation, direct effects between dif- 
ferent epibiotic species (e.g. competition) and between epibionts and hosts (e.g. Wahl in press) may gain greater importance.

Concluding, epibionts have the potential to dramatically increase or decrease the mortality of their hosts. Direct effects of epibiosis have frequently been described (reviewed in Wahl, 1989 and Wahl in press). The two investigations presented here reveal strong indirect effects that operate via the presence of a third species (the consumer in this case). These indirect effects occurred due to the presence of the epibionts and not because epibionts happen to colonize individual hosts that aleady differ in other characteristics that attract or deter consumers. Crabs were unable to discriminate between clean and cleaned mussels, which previously had been epibiotized by barnacles (attractive) or hydrozoans (repulsive), and urchins preyed with equal intensity on clean Sargassum and on cleaned Sargassum which previously had carried the attractive epibiont Bugula neritina (Wahl \& Hay, 1995).

The epibionts affected their hosts' mortality via influencing predator behaviour by enhancing or masking chemical cues or (in the case of the hydrozoancrab interaction) by repelling the contacting predator. Because predation pressure changed as a consequence of altered behaviour and not an abundance increase of the predator, this effect would qualify as an 'interaction modification', as opposed to an 'interaction chain' with serial direct effects (Wootton, 1993).

We are aware of only one study which described similar types of indirect effects. Schmitt (1987) investigated the predation of various species (lobster, octopus, whelk) on gastropod and bivalve prey. He found that by the addition of a prey species, more predators were attracted and predation pressure increased on all prey species. These interactions favored spatial segregation of the two prey species, a phenomenon he called 'apparent competition' (see also Menge, 1995 for a comprehensive treatment of the subject). Our shared doom scenario falls in the same category of indirect effects. For instance, epibiotic barnacles increase predation on fouled mussels. Probably as a consequence of this, in nature, barnacles and mussels co-occurred less often (epibiotically) in the presence than in the absence of predators. On the other hand, associational resistance does not seem to fit any of Menge's types of indirect effects. It has, however, been described repeatedly from terrestrial (e.g. Root, 1973; Atsatt \& O’Dowd, 1976; Bach, 1980) and marine environments (Hay, 1986; Littler et al., 1986; Pfister \& Hay, 1988). As in some of these earlier studies, associations pro- viding hosts with protection (hydrozoan-mussel) were favoured by the presence of predators.

Up to now we have worked only with generalist predators. It could be rewarding to assess the effects of epibionts on predators that are specialized on particular host species and that therefore may not have the physiological or behavioral flexibility to switch to an alternative food when their prey has become less attractive or unrecognisable due to epibiosis.

Because epibiosis creates a new interface between a host and its environment it may be expected that many other interactions, for example with physical factors, with conspecifics, with parasites, etc., may also be modified. The direct and indirect effects of epibiosis on community dynamics are doubtlessly worth investigating more thoroughly.

\section{References}

Atsatt, P. R. \& D. J. O’Dowd, 1976. Plant defense guilds. Science 193: 24-29.

Bach, C. E., 1980. Effects of plant diversity and time of colonization on a herbivore-plant interaction. Oecologia 44: 319-326.

Barkai, A. \& C. McQuaid, 1988. Predator-prey role reversal in a marine benthic ecosystem. Science 242: 62-64.

Bernstein, B. B. \& N. Jung, 1979. Selective pressure and coevolution in a kelp canopy community in Southern California. Ecol. Monogr. 493: 335-355.

Connell, J. H. \& R. O. Slatyer, 1977. Mechanisms of succession in natural communities and their role in community stability and organization. Am. Nat. 111: 1119-1144.

Cronin, G. \& M. E. Hay, 1996. Susceptibility to herbivores depends on recent history of both the plant and animal. Ecology 77: 15311543 .

Feifarek, B. P., 1987. Spines and epibionts as antipredator defenses in the thorny oyster Spondylus americanus Hermann. J. exp. mar. Biol. Ecol. 105: 39-56.

Gil-Turnes, M. S., M. E. Hay \& W. Fenical, 1989. Symbiotic marine bacteria chemically defend crustacean embryos from a pathogenic fungus. Science 246: 116-118.

Hay, M. E., 1986. Associational plant defenses and the maintenance of species diversity: turning competitors into accomplices. Am. Nat. 128: 617-641.

Lampert, W. \& U. Sommer, 1993. Limnoökologie. Georg Thieme Verlag Stuttgart, New York, 440 pp.

Littler, M. M, P. R. Taylor \& D. S. Littler, 1986. Plant defense associations in the marine environment. Coral Reefs 5: 63-71.

Menge, B., 1995. Indirect effects in marine rocky intertidal interaction webs: patterns and importance. Ecol. Monogr. 65: 21-74.

Menge, B. \& J. P. Sutherland, 1987. Community regulation: variation in disturbance, competition, and predation in relation to environmental stress and recruitment. Am. Nat. 130: 730-757.

Pfister, C. A. \& M. E. Hay, 1988. Associational plant refuges: convergent patterns in marine and terrestrial communities result from differing mechanisms. Oecologia 77: 118-129. 
Prescott, R. C., 1990. Sources of predatory mortality in the bay scallop Argopecten irradiance (Lamarck): interactions with seagrass and epibiotic coverage. J. exp. mar. Biol. Ecol. 144: 63-83.

Root, R. B., 1973. Organization of a plant-arthropod association in simple and divers habitats: the fauna of collards (Brassica oleracea). Ecol. Monogr. 431: 95-120.

Ryland, J. S., 1976. Physiology and ecology of marine bryozoans. Adv. mar. Biol. 14: 285-443.

Schmidt, M. \& W. Gnatzy, 1987. Contact chemoreceptors on the walking legs of the shore crab, Carcinus maenas. Ann. N.Y. Acad. Sci. 1987: 589-590.

Schmitt, R. J., 1987. Indirect interactions between prey: apparent competition, predator aggregation, and habitat segregation. Ecology 68: 1887-1897.

Sommer, U., 1995. An experimental test of the Intermediate Disturbance Hypothesis using cultures of marine plankton. Limnol. Oceanogr. 40: 1271-1277.

Sousa, W. P., 1979. Experimental investigations of disturbance and ecological succesion in a rocky intertidal community. Ecol. Monogr. 49: 227-254.
Threlkeld, S. T., D. A. Chiavelli \& R. L. Willey, 1993. The organization of zooplankton epibiont communities. Trends Ecol. Evol. 8: $317-321$

Wahl, M., 1989 . Marine epibiosis. I. Fouling and antifouling: some basic aspects. Mar. Ecol. Progr. Ser. 58: 175-189.

Wahl, M. (in press). Living attached: aufwuchs, fouling, epibiosis. In Nagabhushanam, R. \& M. F. Thompson (eds), Fouling Organisms of the Indian Ocean: Biology and Control Technology. Oxford \& IBH Publ. Co. Put Ltd, New Delhi: 31-83.

Wahl, M. \& M. E. Hay, 1995. Associational resistance and shared doom: effects of epibiosis on herbivory. Oecologia 102: 329-340.

Wootton, J. T., 1993. Indirect effects and habitat use in an intertidal community: interaction chains and interaction modifications. Am. Nat. 141: 71-88.

Zimmer-Faust, R. K., C. M. Finelli, N. D. Pentcheff \& D. S. Wethey, 1995. Odor plumes and animal navigation in turbulent water flow: a field study. Biol. Bull. 188: 111-116. 